\title{
Examining lived experiences in a professional development program for online teaching: A hermeneutic phenomenological approach
}

\author{
Brent Philipsen \\ Vrije Universiteit Brussel, Elsene, Belgium \\ Jo Tondeur, \\ Vrije Universiteit Brussel, Elsene, Belgium and Ghent University, Ghent, Belgium \\ Bram Pynoo, Silke Vanslambrouck, Chang Zhu \\ Vrije Universiteit Brussel, Elsene, Belgium
}

\begin{abstract}
The increased number of courses taught in an online environment has led to more teachers in need of professional development for online or blended teaching. Although various professional development programs have been scrutinised, only a few studies integrate the feelings of teachers during their professional development process. Teachers' feelings form an inherent part of their teacher-selves and are reflected in their everyday practice. Therefore, this study uses a hermeneutic phenomenological research method to examine the lived experiences - the feelings - of educational staff within a professional development program that targets online and blended teaching. The results indicate that teachers experience a large range of feelings and that these fluctuate throughout the program. These include positive feelings of connectivity, responsibility, and satisfaction, but also more negative feelings of chaos and frustration. The recognition and understanding of these feelings can illuminate particular aspects of professional development that are experienced more positively or negatively, which can guide further efforts for qualitative improvement.
\end{abstract}

\section{Theoretical background}

\section{Teacher professional development for online and blended teaching}

Many teacher professional development (TPD) initiatives have been developed in order to immerse teachers in the possibilities of online and blended teaching (OBT) (e.g., Philipsen, Tondeur, \& Zhu, 2016). An initial literature study demonstrates that the design features and factors of a successful TPD for OBT are very similar to those of a general TPD. Both general and OBT TPD emphasise a thoughtful duration (Consuegra \& Engels, 2016), the need for professional and peer support (Desimone \& Garet, 2015), active learning (Consuegra \& Engels, 2016; Gregory \& Salmon, 2013), the relationship between theory and practice, and the experience of a TPD's relevance (Hallas, 2006; Wilson, 2012). Thus, general TPD and TPD for OBT appear quite similar at first sight. However, a possible difference can be identified in the teacher's personal development level, which involves the identification of one's teacher-self in an online environment (Baran, Correia, \& Thompson, 2011). In addition, online teaching can be seen as new way of arranging, supporting, and guiding learning activities (Salmon, 2011) that repositions the persona of the teacher-self into a mode that is (usually) new and digital. While more differences can certainly be identified, it is the pivotal role of the teacher's professional identity and teacher-self in OBT that appears to be one of the most documented (e.g., Baran et al., 2011).

\section{Teachers' lived experiences with OBT: The role of professional identity and feelings}

If teachers' professional identities and teacher-selves may play a pivotal role within TPD for OBT (e.g., Baran et al., 2011), this makes an examination of the effects of a training program on that professional identity an interesting proposition. However, it is not easy to grasp the complex and ongoing process of the development of teachers' professional identities (Hsieh, 2015). One way of examining and approaching teachers' professional identities, or what Kelchtermans (2005) terms their teacher-selves, is by means of teachers' 
feelings (e.g., O'Connor, 2008). This study notes a distinction between teachers' feelings and their emotions. Both terms are commonly used, yet defining them can be strikingly challenging. Their differences are outlined by Scherer (2005), who points out that emotions are essentially an innate trait of human beings, which are elicited by a stimulus event and are appraisal driven (Scherer, 2005). By contrast, feelings can be seen as a response to a certain subjective emotional experience (Scherer, 2005). In an educational context, the following example might create some clarity: The emotion of fear of losing one's job as a teacher can elicit a feeling of responsibility to do whatever it takes to keep that job. The same emotion might also elicit a feeling of resentment at not being recognised for all the hard work one has already done. Thus, emotions can elicit a vast range of feelings. However, this is a highly debated field, and one in which consensus has not yet been attained (Scherer, 2005).

Feelings are of "fundamental importance in teaching and to teachers" (Nias, 1996, p. 293), and teachers experience a vast range of feelings throughout their careers (Hargreaves, 2005). Recent research shows that teachers' feelings affect their memory performance and the fluency of their decision-making and could therefore also affect their ability to learn (Reber \& Greifeneder, 2016). Such feelings comprise an important and selfevident aspect of the practice of teaching (Kelchtermans, 2005). Moreover, when teachers invest their selves in their profession, their feelings and professional identities often become merged with each other (Nias, 1996). However, recent literature does not integrate these feelings when evaluating professional development initiatives, and particularly not when these are targeted at OBT. Teacher professional development research often adopts an effectiveness perspective, while neglecting the personal level (Evans, 2014). In order to address this gap, this study uses a hermeneutic phenomenological approach, which is a suitable and valid approach for examining teachers' feelings during a certain phenomenon (van Manen, 2015), in this case TPD for OBT. Teachers' feelings are understood as the ways in which teachers experience certain moments and live through particular phenomena. In short, they are concerned with their experiences (van Manen, 2015). Lived experiences shape teachers' ideologies and affect how they perceive themselves in their classroom practice (Kenyon, 2017). In addition, they are closely related to teachers' professional identity construction (Becker, 2013). Therefore, this study approaches the professional identity of teachers by examining their lived experiences during a particular phenomenon, namely a TPD for OBT. This was done by investigating which feelings lie at the base of this experience. In this way, the study sought to understand how teachers feel during a TPD for OBT, which can inform us about their lived experience of the training program and their professional identity. Figure 1 presents a conceptual approach that demonstrates where this study positions teachers' feelings towards their larger professional identity. The study focused solely on the inner circle, namely, the teachers' feelings.

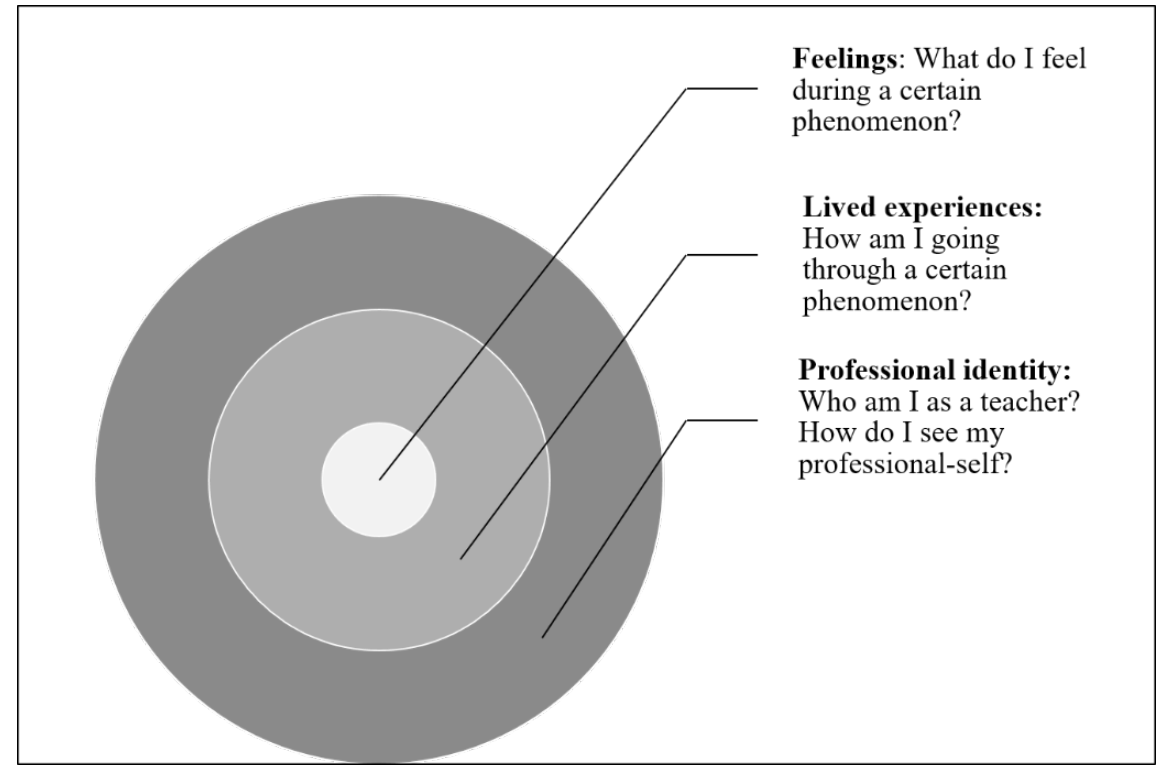

Figure 1. Conceptual approach 


\section{The training program and the purpose of the study}

\section{Introduction to the program}

The training program was co-designed with Toll-net, an organisation that targets technology-enhanced lifelong learning and is situated in Flanders (the Dutch-speaking part of Belgium). The co-constructed blended training program sought to immerse teachers in the world of online teaching. The focus of the program was twofold and consisted of a focus on teaching online, which meant that most of the attention was directed to teaching with technology and developing a vision of online teaching; and a focus on the teacher's role and professional identity in an online learning environment. The program started at the beginning of February 2017 and lasted until the middle of June 2017. The following six modules were offered: (a) Good to know (Why do you want to offer online or blended teaching?); (b) ICT and learning (Developing a vision of teaching in an online or blended way); (c) The perspective of the online learner; (d) Learning technologies; (e) The design of e-material; and finally (f) The development of e-material. The trainers held three face-to-face supervision moments, in addition to one that was conducted in an online meeting room. The focus on the professional identities of teachers in an online environment and how these related to their feelings (O'Connor, 2008) meant that part of one of the face-to-face supervision moments was dedicated to that specific subject.

The trainers invited all the participants $(n=10)$ to an initial face-to-face moment, which formed the start of the training program. They provided support and feedback and set exercises throughout the duration of the program. After the first meeting moment, the trainers planned face-to-face and online supervision moments and followed the individual progress of each participant. The program was based on several theoretical underpinnings: a thoughtful duration (e.g., Consuegra \& Engels, 2016) in which we did not opt for a single one-shot training, but rather an intensive longer period of time; the need for professional and peer support (e.g., Philipsen et al., 2016), which we provided by means of feedback sessions and stimulated by requiring peer-feedback on the program's online learning platform; active learning (e.g., Desimone, 2009), which was stimulated by allowing the participants to actually experience what they were learning. For example, we offered the participants an online supervision session in an online meeting room (Vitero). This allowed them to actively experience what they were learning about, while actually learning the very same subject. In addition, we linked theory and practice (e.g., Hallas, 2006) by co-constructing the program using both scientific and practical input; and finally, we added relevance to the program (e.g., Wilson, 2012) by implementing an online questionnaire. This was a validated technological, pedagogical, and content knowledge - TPACK - questionnaire developed by Scherer, Tondeur, and Siddiq (2017). The results of the questionnaire were used by the trainers to fine-tune the course content to the participants' current TPACK level.

\section{Purpose of the study}

This study aimed to examine the lived experiences of five participants in a TPD program targeting OBT by means of a hermeneutic phenomenological approach. During the analysis, the interpretative focus of the researchers was guided by the question of how the participants felt during the program. Therefore, the specific focus of this study was: How do the participants in a TPD targeting OBT feel during the PD process? Many studies that report on TPD for OBT report on the participants' gains in knowledge, skills, or attitudes (e.g., Comas-Quinn, 2011). However, it can be argued that some TPD programs unfortunately do not examine the teachers' feelings during the program. This focus on feelings is more prevalent in more general TPD literature (e.g., Hargreaves, 2005; Kelchtermans, 2005), although it remains a minor aspect of the current literature, particularly in relation to OBT. Examining an experience from the inside by means of feelings is a good way to produce a description of a lived experience (van Manen, 2016). We would like to stress that this study did not investigate nor report the perceived effectiveness of the training program, but solely on the lived experiences. While an examination of the program's effectiveness is undoubtedly an interesting topic, this is not the aim of the present article. 


\section{Methodology}

\section{Hermeneutic phenomenology}

Hermeneutic phenomenology seeks to gain a thorough understanding of lived experiences (van Manen, 2016). It does so by asking how a certain phenomenon is experienced by the person who lives through it in order to better understand the phenomenon examined (Ottenbreit-Leftwich, Glazewski, Newby, \& Ertmer, 2010; van Manen, 2016). A phenomenological method seeks to describe and interpret lived experiences and their meanings in a rich and deep way (van Manen, 2016). Lopez and Willis (2004) stress the importance of going beyond solely descriptive accounts of the lived experience, and of searching for the meanings gleaned from the narratives produced by the participants. The lived experiences should be portrayed in texts that subsequently can be interpreted for their meaning (Lindseth \& Norberg, 2004). As the science and art of interpretation and meaning (Henriksson \& Friesen, 2012), hermeneutics is concerned with the study of texts (Lindseth \& Norberg, 2004). As Henriksson and Friesen write: "Hermeneutic phenomenology is consequently the study of experience together with its meanings. Like hermeneutics, this type of phenomenology is open to revision and reinterpretation: it is about an openness to meaning and to possible experiences" $(2012$, p. 1).

\section{Data sources}

Phenomenological research requires that one focuses on making meaning out of lived experiences (Friesen, 2012; van Manen, 2016). In essence, we “'borrow' other people's experiences and their reflections on their experiences in order to better be able to come to an understanding of the deeper meaning or significance of an aspect of human experience" (van Manen, 2016, p. 12). Furthermore, because the meaning and the understanding of lived experiences must originate from the interpretation of texts (Lindseth \& Norberg, 2004), the data sources for the current study needed to be suitable for this type of research. The basic goal that guides phenomenological research is to grasp the complex nature of a particular phenomenon as a human experience (van Manen, 2016). This means that phenomenological inquiry relies on the collection of pre-reflective, remembered moments (Adams, Yin, Vargas Madriz, \& Mullen, 2014). Therefore, we made use of three different data sources for the current research, namely, protocol writing (descriptions of lived experience), interviews, and observation notes (van Manen, 2016).

The protocol writings were collected as part of the reflective writings produced during the TPD program. The participants were asked to post these reflections in an online portfolio. They were asked how they experienced certain moments (e.g., the first contact moment) and how they felt during these moments. These texts provided an original data source, with which the researchers were able to work (van Manen, 2016). They also put people into a reflective mode, which differed from the following data source, namely the interview, in which the participants were more immediately involved (van Manen, 2016).

The main data source for this study was a hermeneutic phenomenological interview. This serves a different function from interviews used for other types of qualitative research. The current study did not seek generalisations, nor did we ask why certain feelings appeared more often than others. Rather, we sought to examine how the participants experienced the TPD program by examining which feelings they experienced as they lived through it. This had implications for the interviewing method. There were two interviews for each participant, which were not held in a formal setting but in a place chosen by the participants. It was necessary for them to feel comfortable in that specific environment due to the highly personal nature of the interview (van Manen, 2016). Questioning somebody about their feelings in relation to their experiences at a particular moment does not involve everyday questions, and therefore needs to occur in an atmosphere of trust. Some examples of the questions asked included "How did you feel when you entered the room during the first contact moment and you first met all those people?", "How did you feel when you were having trouble getting to the meeting point?", and "How did you feel when your colleagues at school started to ask what you were doing in this training program?" 
In addition to protocol writing and interviewing as a data source, we also used observation notes. These notes were compiled throughout the entire professional development program. They were collected whenever there was a contact moment or an online meeting moment. The notes were based on the participants' contributions on the online learning platform. The observation notes and the protocol writings were used mainly to complement the hermeneutic phenomenological interviews. The interviews were the main data source, and the findings from this data source were compared to the protocol writings and the observation notes in order to check whether they were congruent. If any notable differences or dissonances were identified, this was noted in the results. However, no notable differences were found between the different data sources used in this study.

\section{Data analysis}

The textual data was imported into NVivo 10 and was analysed by means of an inductive approach that used thematic analysis (Braun \& Clarke, 2006; van Manen, 2016), without any predetermined categories (Patton, 2015). The study conceptualised a theme as the form by which we sought to capture the phenomenon of professional development for OBT, and to make sense of something that basically "gives shape to the shapeless" (van Manen, 2015, p. 12) in an experiential structure. A thematic analysis offers a way of identifying and uncovering the underlying themes in a given data set (Braun \& Clarke, 2006). Although it is extensively used as a method of analysis, it often remains inadequately defined (Boyatzis, 1998, Roulston, 2001). Therefore, it is important to clarify the approach used in elucidating the thematic aspects of a phenomenon in a textual data set, particularly in phenomenological research (van Manen, 2015). To illustrate this, we can note that three approaches are generally applied in order to uncover thematic aspects. These are a holistic approach that targets the underlying meaning of the entire text, a selective approach in which one examines which phrase(s) or statement(s) are considered to illuminate the phenomenon being examined, and a detailed approach in which all the sentences are individually examined with regard to their significance to the phenomenon (van Manen, 2015). In this study a selective approach was used.

Three main general steps were followed with regard to the process of thematic analysis (Braun \& Clarke, 2006), namely, the transcription of the data, the coding the data, and the analysis of the data. After all the transcripts were imported into NVivo 10, we used the selective approach and conducted an initial open coding (Miles \& Huberman, 1994). The following step consisted of the axial coding (Miles \& Huberman, 1994), in which the single codes from the open coding process were grouped into larger categories. These categories form the basis of the themes discussed in the Results section of this article. For example, the larger category feelings of satisfaction encompasses two smaller subcategories, namely, feelings of pride and feelings of being happy. All the interviews were largely coded by one author. Additionally, a second author was asked to code some of the interviews in order to examine the reliability of the current study and to assess the consistency of the two different coders. An interrater reliability score was derived from a coding comparison query in NVivo 10 in which the second coder also independently coded the first four interviews. Cohen's kappa (.70) was considered as substantial agreement between the two coders on the first four interviews. A discussion was held between the two coders to refine the code book in order to resolve any disagreements. The first coder then continued to code the following six interviews. Finally, all the authors were involved in the construction of the final themes. Figure 2 presents this process.

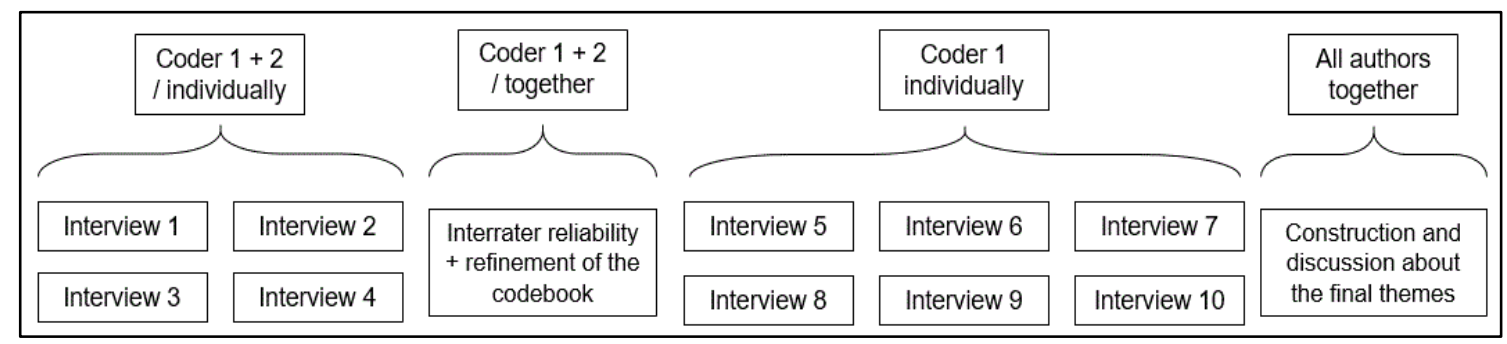

Figure 2. Coding process and construction of the final themes 


\section{The role of the researcher and ethics of phenomenology}

As researchers, we needed to recognise and acknowledge that our own experiences and preconceptions influenced our interpretations when examining and interpreting the lived experiences of the study's participants (Lopez \& Willis, 2004). Moreover, researchers involved in phenomenological research need to be aware that they "cannot step outside the moral values" (van Manen, 2015, p. 2) of human science research. This implies that one remains aware that one's research may affect institutions and people in a long-term way, and that it may even affect the researcher (van Manen, 2015). In our case, our perspective was rooted in our experiences as both practitioners and researchers. As practitioners in teacher education programs, we were frequently confronted with the feelings and experiences of pre-service teachers during the course of their internships within several educational institutions and at various educational levels. In addition, we also recognised our own feelings during teaching processes and professional development initiatives. As researchers, we had identified that TPD programs rarely paid attention to how teachers felt during their professionalisation process. This was particularly the case when the program targeted online or blended teaching, which motivated us to conduct the present study. We therefore acknowledge that our experiences in this regard may influence our interpretations. During the data analysis procedure, we held frequent discussions on the feelings identified, together with their descriptions. This was done in order to remain vigilant regarding our own preconceptions and in order to obtain a valid description of the phenomenon examined (van Manen, 2015).

\section{The context of the study and the participants}

A professional development course was co-designed and developed with Toll-net. Toll-net is a Flemish organisation that provides training for technology-supported lifelong learning. The program originated from Toll-net's existing training programs, which were supplemented by recent scientific insights provided by the researchers. This led to the co-creation of a new, scientifically supported TPD program that targeted online teaching. Ten participants enrolled in the program, and five volunteered to participate in the current study. These five participants came from various backgrounds, yet all had similar reasons for participating in the TPD program. They all faced a specific real-life problem related to online or blended teaching. During the TPD program, they were all asked to focus on their specific real-life problem. This was done in order to strive as much as possible for a useful end product. All the participants met at a real-life kick-off moment at which the program was presented, and at which all the participants got the chance to meet each other. During the first meeting, all the participants were informed about the research and signed an informed consent form indicating their agreement. A sample size of five participants could be deemed too low, although that is considered a suitable sample size for hermeneutic phenomenology (De Gagne \& Walters, 2010). The ideal number of participants in a hermeneutic phenomenological study depends on the nature of the study (Laverty, 2003), but a smaller number of participants is generally preferred in order to clearly portray their lived experiences (e.g., Crimmins, 2017; Ottenbreit-Leftwich et al., 2010; van Manen, 2016). Table 1 presents basic information on this study's five participants. Their names have been adjusted to respect their privacy. 
Table 1

\begin{tabular}{|c|c|c|c|c|c|}
\hline Name & Gender & Age & Current employment & $\begin{array}{l}\text { Previous } \\
\text { experience } \\
\text { with OBT }\end{array}$ & Reason for participation \\
\hline Claire & $\mathrm{F}$ & 26 & $\begin{array}{l}\text { College lecturer and } \\
\text { researcher }\end{array}$ & No & $\begin{array}{l}\text { To gain information on designing, } \\
\text { developing, and guiding e-courses. }\end{array}$ \\
\hline John & $\mathrm{M}$ & 46 & Secondary school teacher & No & $\begin{array}{l}\text { To gain information on the } \\
\text { rationale behind developing a } \\
\text { school-appropriate app. }\end{array}$ \\
\hline Julianne & $\mathrm{F}$ & 41 & Secondary school teacher & No & $\begin{array}{l}\text { To gain deepened insight into the } \\
\text { implementation possibilities of } \\
\text { OBT in a high school } \\
\text { environment. }\end{array}$ \\
\hline Meryl & $\mathrm{F}$ & 45 & $\begin{array}{l}\text { Pedagogical counsellor for } \\
\text { the implementation of } \\
\text { OBT in adult education }\end{array}$ & $\begin{array}{l}\text { Yes } \\
1 \text { year }\end{array}$ & $\begin{array}{l}\text { To gain more detailed information } \\
\text { on why and how OBT can be } \\
\text { implemented in adult education } \\
\text { and training. }\end{array}$ \\
\hline Nicole & $\mathrm{F}$ & 42 & $\begin{array}{l}\text { Director of competence } \\
\text { and care in a social service } \\
\text { agency }\end{array}$ & No & $\begin{array}{l}\text { To gain more detailed information } \\
\text { on why and how OBT can be } \\
\text { implemented in the courses } \\
\text { provided by her social service } \\
\text { agency. }\end{array}$ \\
\hline
\end{tabular}

\section{Results}

The study identified five distinct feelings among the participants. This section presents those feelings, together with several quotations to support the findings. These five feelings were found in all the participants and are therefore presented as core feelings. In this section, these feelings are ordered from more positive feelings to more negative feelings. This does not mean that they are exclusively experienced as either negative or positive.

\section{Feelings of connectivity}

In this study, the participants' feelings of connectivity were identified as a sense of a mutual endeavour and a recognition that one learns from one another. Even before arriving at the first training moment, some of the participants were already wondering who else would be present: "I was very curious about who was going to be there, and I always find it nice to know why they are there. Because there are many kinds of people. I always find it interesting, all those different people" (Meryl). Meryl later specified that she likes to work in a group due to the learning possibilities this offers: "I am someone who likes to hear if I am doing a good job every now and then, and if the answer is no, then I want to know why so I can adjust my work." As already noted, in addition to the recognition that one can learn from one another, the participants also stated that they felt a sense of connectedness and of being in the training program together. Claire indicated that she immediately felt a connection with Meryl during the first moments of meeting:

I immediately felt a match with Meryl. I do not know if this was because I was sitting next to her, but we started talking right away. You can notice that she is a very open person and that attracts me. What she does in her professional life and what I do, we have some similarities and you do not have that with everyone.

During her second interview, Claire also stated that the social contact involved made her feel more connected to the professional development program itself: 
I liked it a lot that we met on a regular basis so that we could talk with each other. During the first meeting we chose our communication channel for maintaining our social contact. That made me feel more connected to this course because if we wanted to we could have done everything online. So, in that way I appreciated that [the social contact] a lot.

\section{Feelings of satisfaction}

As with the previous feeling, all the participants indicated that they felt satisfied during and at the end of the program. These feelings of satisfaction were related to feelings of pride and being happy. The general sense of satisfaction was extremely diverse throughout the entire program. For some of the participants, this was related to small positive experiences, such as that of Julianne:

All the things that I gained from this course, to which I said, "Oh that is nice", are already being used by my own colleagues here at school [...] that makes you feel satisfied and makes you want to continue with this course.

Although Julianne referred to the fact that her colleagues were also using the things she saw in the program, Meryl experienced feelings of satisfaction that were related to specific course content. She said: "The section in the beginning was very positive for me. The vision regarding education and distance education, that was ideal. I think that all schools should start with that. It is a very good exercise." As noted above, the feeling of satisfaction was also formed by feelings of pride. Julianne has already indicated that her colleagues also used the things that she saw in the program, and the following quotation illustrates how this made her feel: "They [her colleagues] always provide feedback and then you often hear immediately that they are enthusiastic about it $[\ldots]$ it makes me proud, it is a personal success."

\section{Feelings of responsibility}

All the participants experienced feelings of responsibility, but they differed with regard to why and to whom they felt responsible. Some of them believed that one is responsible for finishing what one has started. For example, John missed a trip to London with his students because one of the face-to-face meetings occurred at the same time as that trip. Although he admitted that he would rather have gone on the trip, he argued that his responsibility towards his school leader who had approved the training program meant that he should fulfil his engagement and complete the program by attending all the meetings. Claire stated that she felt a responsibility towards the program's trainers to ensure that she was always on time and did what was asked of her: "I do not want to be late. What would they think of me? I need to make a good impression and make a good start [...] I want to do it well and make sure I respect the deadlines." Although John and Claire felt responsibility - or accountability - towards other people, Nicole felt a responsibility to follow the course due to her function and the era in which we live:

I feel the need to adapt to the times and I think it is important that as a leader you know what you are talking about. I have to show that I am also looking for information, and I try to convey my enthusiasm to my team.

Julianne gave similar reasons based on her function. But it was also her personal vision that made her feel responsible for following this course and informing her colleagues about it:

I presented my e-portfolio to my colleagues because they often ask what I am doing. I then tell them how they can use it [e-learning] and they like that [...] it is also my vision and responsibility to implement this [e-learning] here at our school. I still think it is cool that I am actually succeeding in spreading my vision. 


\section{Feelings of chaos}

The participants' feelings of chaos refer to a range of lived experiences that related to a sense of confusion. The participants often indicated a sense of confusion and chaos during the professional development program. For example, while Meryl was riding home with another participant after the introductory session she asked herself, "What was that all about? Did I actually enrol myself for this?" During the introduction, the participants were given an assignment to create a portfolio and were able to choose which platform they would use. Most of the participants appeared to experience this as too unclear and were left with a sense of confusion: "It was one big chaos. One big chaos. Regarding my portfolio, I started over again three times because I did not know how and what ... it was chaos" (Meryl). Nicole stated that the program may have used too many different learning and communication platforms, although she also indicated that this may be inherent to such a training program: "It was really chaotic for me because of the different channels and tools [...] but maybe this is specific to such a trajectory? They [the trainers] also have to learn how to work with the tools and search for input." The feeling of chaos that was apparent in all the participants was therefore not necessarily negative. For some, the amount of freedom offered was too overwhelming and confusing. Others indicated afterwards that, although there was considerable chaos, it helped them to discern the tools they needed. They said that they ultimately found their way in creating a digital portfolio among all the possible tools:

Those learning paths often had a lot of content and I asked myself what was expected of me. Yes, there was chaos, but, on the other hand, I do feel that I found my way through all of that, and I was able to get the information that I needed. (Claire)

\section{Feelings of frustration}

All the participants expressed feelings of frustration throughout the program, which were also linked to the smaller subcategory of stress and a feeling of being unsatisfied. One of the main points of frustration was the online intervision moment. The participants had to download a tool that enabled them to hold an online meeting. The underlying idea was that they should be able to meet digitally, while also experiencing an example of a tool suitable for online meetings. However, some of the participants had trouble installing the tool, or their microphone did not work, or they found it irritating that their messages could only be a limited number of characters long:

I disliked that part [the online meeting] the most. It felt as if you were detached from everybody. You were sitting there alone behind your computer, wearing your headset, and that tool did not work immediately, so I got a bit frustrated. (Julianne)

To start with, the installation of the tool was very difficult. John had already told me that there were many problems with the tool and that his microphone did not work. You need a tool that is super easy. Plus we did not see each other. I find that stupid [...] You were staring at that screen and if you wanted to say something you needed to press a certain button, which did not work a single bit. (Meryl)

Of all the participants, John reported the most frustrations. He sometimes felt that the program did not offer him what he had expected, and that he would have liked more feedback:

I like the program but it does not weigh up to the teaching hours that I missed in my class. For me, it did not always deliver what I expected. I missed twenty-eight hours in the same class. I do not really mind this if I get a return on my investment and that I missed sometimes.

\section{Discussion}

This study has sought to examine the lived experiences of five participants in a professional development program targeted at learning to teach online. Their lived experiences were examined by depicting their feelings 
(van Manen, 2015) during the program. On the basis of a hermeneutic phenomenological study, five main feelings were identified that were apparent in all five participants. These were feelings of chaos, connectivity, satisfaction, responsibility, and frustration. Although these five feelings were definitely not the only feelings they experienced, they were the only ones reported by all five participants. These feelings align to a certain degree with previous research on teachers' feelings (Chen, 2016). Chen (also identified five distinct teacher feelings, namely, joy, love, sadness, anger, and fear. The current study's identification of frustration can be compared to Chen's identification of anger. Both lead to a situation in which the teacher feels a sense of being displeased with the current practice. In Chen's study, joy and love are described as a profound sense of contentment. This can be aligned with the current study's identification of the feeling of satisfaction and being pleased with one's professional development. As with the study of Saunders (2013), the participants in this study reported both positive and more negative feelings during their professional development trajectory. Saunders (2013) also highlights how feelings can affect and interconnect with a teacher's professional identity. This means that they can experience extremely intense feelings when they are asked to alter their practice (Scott \& Sutton, 2008). This is particularly true when the aim of the TPD program is online teaching, which can be seen as a new way of orchestrating teaching and learning (Salmon, 2011). Scott (2016) demonstrated that some teachers first change their teaching beliefs prior to changing their practice, while other teachers first change their practice and then change beliefs when adapting to online teaching. This means that when teachers are facing a change, it is difficult to predict how they will process this change. This is particularly true when this change entails something as complex as teachers' professional identities (Baran et. al., 2011) and feelings.

Teachers' professional identities are not only related to their self-perception as professionals (Jonker, März, \& Voogt, 2018), but are also related to their relationships with their colleagues. Teachers care about how others see and judge them (Saunders, 2013). Therefore, the feeling of connectivity identified in this study (e.g., Claire's question, "What will they think of me?) may tell us something about a person's professional identity. As noted in the Introduction, we can examine teachers' professional identities by studying how they feel (O'Connor, 2008) during a certain phenomenon. Guided by the aim of our study, which was to examine the participants' lived experiences during a TPD program for online teaching, we can now state that they felt five distinct, yet related, feelings. Elaborating on this may give us an idea of what these feelings tell us about the professional identities of these teachers. The identification of these five feelings can indicate what our participants consider to be important. If we stay with the example of Claire, we might suggest that she cares a great deal about how other people see her and that she wants to make a good impression. This is supported by previous studies that demonstrate that people do indeed care about how others see them during a TPD program (Saunders, 2013). Furthermore, people want to be seen by their peers during TPD programs (Bills, Giles, \& Rogers, 2016). Therefore, if our participants report feelings of connectivity and being seen (Bills et al., 2016), and if these feelings are interconnected and related to their professional identities (Saunders, 2013), then we could suggest that their professional identities can entail inter alia a positive social presence. Thus, their feelings can indicate how our participants construct their professional identities, which is of considerable importance in a TPD program that targets online teaching (Baran et al., 2011). This means that coming to understand the feelings of teachers or practitioners during a TPD program for online teaching can give one a better idea of how they see themselves as online teachers. This can lead, in turn, to increased knowledge regarding how to design TPD programs for online teaching.

\section{Implications for the design of teacher professional development for OBT}

The feelings reported by the participants in this study demonstrated their lived experience of a TPD program for teaching online. As such, they may help us to better understand how they view their professional identities. In addition, they indicate specific points of interest with regard to the design of future TPD programs for OBT. The feelings of frustration highlighted several points for improvement. We now know that the participants appreciated the freedom they experienced in choosing their portfolio tool, for example, but that there should be a limit regarding how far this freedom can go. Their experiences suggest that it would be better to provide them with certain examples from which they can choose. This would maintain the feeling of freedom, yet still support them by offering them a set of possible tools. The same is true of the feeling of chaos. The program, and particularly its online aspect, should contain a clear overview of where the participants are in the program, and of what is expected from them and by when. The trainers, for their part, should ask more frequently how the 
participants are progressing, and if there are any problems. For example, John stated that he wanted more feedback, and this is in keeping with Bills et al. (2016) who state that people want to be seen in professional development activities. In this case, John was actually sending a message that he wanted to be seen and heard, and that this affected how he felt during the program. Therefore, trainers should not only be easily approachable, but they should also give considerable and considerate thought to the delicate balance between providing room for self-directedness and giving guided support. Moreover, trainers need to become aware of and sensitive towards teachers' feelings during professional development initiatives. Teachers' feelings and their ways of expressing them may offer considerable information that can be valuable in the development and support of professional learning experiences. It would be interesting to see further research that targets this aspect.

While this applies to any TPD, the lived experiences of the people participating in a TPD program for online teaching need to not only be acknowledged by policy makers, administrators, and trainers (Saunders, 2013), but they should also be acknowledged by school leaders and professional development coordinators. Teacher change during professional development programs can lead to intense feelings (Scott \& Sutton, 2008), and TPD programs should therefore provide the time and space to allow people to discuss these feelings (Saunders, 2013). Moreover, it should be made clear that these feelings are a completely natural part of teacher change and of participation in a TPD program (Schmidt \& Datnow, 2005).

\section{Limitations and suggestions for further research}

Further research could provide a more in-depth examination of the relationship between teachers' feelings and their professional identities. This could further our understanding of how specific feelings arise and which contextual circumstances influence this process. In addition, it would be interesting to discover whether teachers participating in other TPD initiatives report similar feelings. Both qualitative and quantitative approaches will be able to provide greater insight into this relatively under-examined aspect of TPD for online teaching. Future research could consider whether or not these same feelings occur in different contexts and with different sample sizes.

\section{Conclusion}

This study started with the aim of examining our participants' lived experiences during a professional development program that targeted online teaching. The results of this hermeneutic phenomenological study indicate five core feelings that were reported by the respondents. The identification of feelings such as frustration, satisfaction, connectivity, responsibility, and chaos may enable us to better understand how the participants perceive themselves as professionals and what matters to them. The identification of the specific feelings of teachers and how they may be related to their profession and their professionalism may require some time and the development of particular skills. This may, in turn, provide an initial indication of how teachers' professional identities are constituted. The understanding of this professional identity construction in relation to professional development for online teaching can benefit researchers and practitioners because it enables deductions to be made regarding the design features of professional development. The feeling of connectivity, which entails interaction and mutual recognition between the participants, was shown to be one of the feelings reported (Bills et al., 2016; Chen, 2016). Given that feelings shape a person's professional identity (Saunders, 2013), this can lead to the tentative conclusion that social interaction and a positive social presence should be acknowledged as an important design feature in the creation of professional development programs that target online and blended teaching.

\section{Acknowledgements}

This study was funded by the Agentschap Innoveren \& Ondernemen (Agency Innovation and Entrepreneurship) and the Agentschap voor Innovatie door Wetenschap en Technologie (Agency for Innovation by Science and Technology) (Project no. 140029). 


\section{References}

Adams, C., Yin, Y., Vargas Madriz, L. F., \& Mullen, C. S. (2014). A phenomenology of learning large: The tutorial sphere of xMOOC video lectures. Distance Education, 35(2), 202-216. https://doi.org/10.1080/01587919.2014.917701

Baran, E., Correia, A.-P., \& Thompson, A. (2011). Transforming online teaching practice: Critical analysis of the literature on the roles and competencies of online teachers. Distance Education, 32(3), 421-439. https://doi.org/10.1080/01587919.2011.610293

Becker, B. A. (2013). The lived experience of professional identity in master nursing academics (Doctoral dissertation). Retrieved from the University of Minnesota Digital Conservancy, http://hdl.handle.net/11299/155565

Beijaard, D., Meijer, P. C., \& Verloop, N. (2004). Reconsidering research on teachers' professional identity. Teaching and Teacher Education, 20(2), 107-128. https://doi.org/10.1016/j.tate.2003.07.001

Bills, A., Giles, D., \& Rogers, B. (2016). 'Being in' and 'Feeling seen' in professional development as new teachers: The ontological layer(ing) of professional development practice. Australian Journal of Teacher Education, 41(2), 106-121. https://doi.org/10.14221/ajte.2016v41n2.7

Boyatzis, R. (1998). Transforming qualitative information: Thematic analysis and code development. Cleveland, OH: Sage.

Braun, V., \& Clarke, V. (2006). Using thematic analysis in psychology. Qualitative Research in Psychology, 3(2), 77-101. https://doi.org/10.1191/1478088706qp063oa

Chen, J. (2016). Understanding teacher emotions: The development of a teacher emotion inventory. Teaching and Teacher Education, 55, 68-77. https://doi.org/10.1016/j.tate.2016.01.001

Comas-Quinn, A. (2011). Learning to teach online or learning to become an online teacher: An exploration of teachers' experiences in a blended learning course. ReCALL, 23(3), 218-232. https://doi.org/10.1017/S0958344011000152

Consuegra, E., \& Engels, N. (2016). Effects of professional development on teachers' gendered feedback patterns, students' misbehaviour and students' sense of equity: Results from a one-year quasi-experimental study. British Educational Research Journal, 42(5) 1-24. https://doi.org/10.1002/berj.3238

Crimmins, G. (2017). Feedback from the coal-face: How the lived experience of women casual academics can inform human resources and academic development policy and practice. International Journal for Academic Development, 22(1), 7-18. https://doi.org/10.1080/1360144X.2016.1261353

De Gagne, J. C., \& Walters, K. J. (2010). The lived experience of online educators: Hermeneutic phenomenology. Journal of Online Learning and Teaching, 6(2), 357-366. Retrieved from http://jolt.merlot.org/vol6no2/degagne 0610.htm

Desimone, L. (2009). Improving impact studies of teachers' professional development: Toward better conceptualizations and measures. Educational Researcher, 38(3), 181-199. https://doi.org/10.3102/0013189X08331140

Desimone, L., \& Garet, M. (2015). Best practices in teachers' professional development in the United States. Psychology, Society and Education, 7(3), 252-263. https://doi.org/10.25115/psye.v7i3.515

Evans, L. (2014). Leadership for professional development: Enhancing our understanding of how teachers develop. Cambridge Journal of Education, 44(2), 179-198. https://doi.org/10.1080/0305764X.2013.860083

Friesen, N. (2012). Experiential evidence: I, we, you. In N. Friesen, C. Henriksson, \& T. Saevi (Eds.), Hermeneutic phenomenology (pp. 39-54). Rotterdam: Sense. https://doi.org/10.1007/978-94-6091-834$\underline{6} 3$

Gregory, J., \& Salmon, G. (2013). Professional development for online university teaching. Distance Education, 34(3), 256-270. https://doi.org/10.1080/01587919.2013.835771

Hallas, J. (2006). Professional development for online teaching practices. In Markauskaite, L., Goodyear, P., \& Reimann, P. (Eds.), Who's learning? Whose technology? Proceedings Ascilite (Vol. 2, pp. 303-311). Sydney: The University of Sydney. Retrieved from http://www.ascilite.org/conferences/sydney06/proceeding/pdf_papers/vol2.pdf 
Hargreaves, A. (2005). Educational change takes ages: Life, career and generational factors in teachers' emotional responses to educational change. Teaching and Teacher Education, 21(8), 967-983. https://doi.org/10.1016/j.tate.2005.06.007

Henriksson, C., \& Friesen, N. (2012). Hermeneutic Phenomenology. In N. Friesen, C. Henriksson, \& T. Saevi (Eds.), Hermeneutic phenomenology (pp. 1-14). Rotterdam: Sense. https://doi.org/10.1007/978-94-6091834-6 7

Hsieh, B. (2015). The importance of orientation: Implications of professional identity on classroom practice and for professional learning. Teachers and Teaching, 21(2), 178-190. https://doi.org/10.1080/13540602.2014.928133

Jonker, H., März, V., \& Voogt, J. (2018). Teacher educators' professional identity under construction: The transition from teaching face-to-face to a blended curriculum. Teaching and Teacher Education, 71, 120133. https://doi.org/10.1016/j.tate.2017.12.016

Kelchtermans, G. (2005). Teachers' emotions in educational reforms: Self-understanding, vulnerable commitment and micropolitical literacy. Teaching and Teacher Education, 21(8), 995-1006. https://doi.org/10.1016/j.tate.2005.06.009

Kenyon, E. A. (2017). Lived experience and the ideologies of preservice social studies teachers. Teaching and Teacher Education, 61, 94-103. https://doi.org/10.1016/j.tate.2016.10.006

Laverty, S. M. (2003). Hermeneutic phenomenology and phenomenology: A comparison of historical and methodological questions. International Journal of Qualitative Methods, 2(3), 21-35. https://doi.org/10.1177/160940690300200303

Lindseth, A., \& Norberg, A. (2004). A phenomenological hermeneutical method for researching lived experience. Scandinavian Journal of Caring Science, 18(2), 145-153. https://doi.org/10.1111/j.14716712.2004.00258.x

Lopez, K. A., \& Willis, D. G. (2004). Descriptive versus interpretive phenomenology: Their contributions to nursing knowledge. Qualitative Health Research, 14(5), 726-735. https://doi.org/10.1177/1049732304263638

Miles, M., \& Huberman, A. M. (1994). An expanded sourcebook: Qualitative data analysis. Thousand Oaks, CA: Sage.

Nias, J. (1996). Thinking about feeling: The emotions in teaching. Cambridge Journal of Education, 26(3), 293-306. https://doi.org/10.1080/0305764960260301

O'Connor, K. E. (2008). "You choose to care": Teachers, emotions and professional identity. Teaching and Teacher Education, 24(1), 117-126. https://doi.org/10.1016/j.tate.2006.11.008

Ottenbreit-Leftwich, T., Glazewski, K. D., Newby, J. T., \& Ertmer, P. A. (2010). Teacher value beliefs associated with using technology: Addressing professional and student needs. Computers \& Education, 55(3), 1321-1335. https://doi.org/10.1016/j.compedu.2010.06.002

Patton, M. Q. (2015). Qualitative research \& evaluation methods. Thousand Oaks, CA: Sage.

Philipsen, B., Tondeur, J., \& Zhu, C. (2016). Exploring digital didactics: An explorative case study on learning to teach online. In J. Novotná, \& A. Jančařík (Eds.), Proceedings of the 15th European Conference on e-Learning (pp. 555-561). Charles University, Prague: Academic Conferences and Publishing International Limited. Retrieved from https://www.researchgate.net/publication/309490413_Exploring_digital_didactics_An_explorative_case_s tudy_on_learning to teach_online

Reber, R., Greifeneder, R. (2016). Processing fluency in education: How metacognitive feelings shape learning, belief, formation and affect. Educational Psychologist, 52(2), 84-103. https://doi.org/10.1080/00461520.2016.1258173

Roulston, K. (2001). Data analysis and 'theorizing as ideology'. Qualitative Research, 1(3), $279-302$. https://doi.org/10.1177/146879410100100302

Salmon, G. (2011). E-moderating: The key to teaching and learning online. New York, NY: Routledge.

Saunders, R. (2013). The role of teacher emotions in change: Experiences, patterns and implications for professional development. Journal of Educational Change, 14(3), 303-333. https://doi.org/10.1007/s10833-012-9195-0

Scherer, K. R. (2005). What are emotions? And how can they be measured? Social Science Information, 44(4), 695-729. https://doi.org/10.1177/0539018405058216 
Scherer, R., Tondeur, J., \& Siddiq, F. (2017). On the quest for validity: Testing the factor structure and measurement invariance of the technology-dimensions in the Technological, Pedagogical, and Content Knowledge (TPACK) model. Computers \& Education, 112, 1-17. https://doi.org/10.1016/j.compedu.2017.04.012

Schmidt, M., \& Datnow, A. (2005). Teachers' sense-making about comprehensive school reform: The influence of emotions. Teaching and Teacher Education, 21(8), 949-965. https://doi.org/10.1016/j.tate.2005.06.006

Scott, C., \& Sutton, R. E. (2008). Emotions and change during professional development for teachers. Journal of Mixed Methods Research, 3(2), 151-171. https://doi.org/10.1177/1558689808325770

Scott, K. (2016). Change in university teachers' e-learning beliefs and practices: A longitudinal study. Studies in Higher Education, 41(3), 382-398. https://doi.org/10.1080/03075079.2014.942276

van Manen, M. (2015). Researching lived experiences (2nd ed.). New York, NY: Routledge.

van Manen, M. (2016). Phenomenology of practice: Meaning giving methods in phenomenological research and writing. New York, NY: Routledge.

Wilson, A. (2012). Effective professional development for e-learning: What do the managers think? British Journal of Educational Technology, 43(6), 829-900. https://doi.org/10.1111/j.1467-8535.2011.01248.x

Corresponding author: Brent Philipsen, brent.philipsen@vub.be

Australasian Journal of Educational Technology (C) 2019.

Please cite as: Philipsen, B., Tondeur, J., Pynoo, B., Vanslambrouck, S., \& Zhu, C. (2019). Examining lived experiences in a professional development program for online teaching: A hermeneutic phenomenological approach. Australasian Journal of Educational Technology, 35(5), 46-59.

https://doi.org/10.14742/ajet.4469 